\title{
On Presumptions, Burdens of Proof, and Explanations
}

\author{
Petar Bodlović
}

\author{
Faculty of Philosophy \\ University of Groningen \\ Oude Boteringestraat 52 \\ 9712 GL Groningen \\ The Netherlands \\ p.bodlovic@rug.nl
}

\begin{abstract}
On the standard view, all presumptions share the same deontic function: they asymmetrically allocate the burden of proof. But what, exactly, does this function amount to? Once presumptions are rejected, do they place the burden of arguing, the burden of explanation, or the most general burden of reasoning on their opponents? In this paper, I take into account the differences between cognitive and practical presumptions and argue that the standard accounts of deontic function are at least ambiguous (because two types of presumptions entail distinct conceptions of the “burden of proof"), and likely implausible. As a result, they require qualifications.
\end{abstract}

Résumé: D'un point de vue courant, toutes les présomptions partagent la même fonction déontique: elles allouent asymétriquement la charge de la preuve. Mais à quoi correspond exactement cette fonction? Une fois les présomptions sont rejetées, imposent-elles la charge de l'argumentation, la charge de l'explication ou la charge la plus générale du raisonnement à leurs opposants? Dans cet article, je prends en compte les différences entre les présomptions cognitives et pratiques et je soutiens que les descriptions courantes de la fonction déontique sont au moins ambigües (parce que ces deux types de présomptions impliquent des conceptions distinctes de la «charge de la preuve»), et probablement peu plausibles. En conséquence, elles nécessitent des modifications.

Keywords: adequacy, asymmetrical allocation, burden of explanation, burden of proof, cognitive presumption, deontic function, Flat Earth, practical presumption. 


\section{Introduction ${ }^{1}$}

The notion of the burden of proof plays an important role in both ordinary and academic parlance. Broadly understood, it denotes the dialogical obligation of a party (e.g., proponent) to support her position once it gets challenged, rejected, or contradicted by the opponent. In law, philosophy and argumentation theory, the burden of proof raises many questions, but one question stands out in terms of popularity and practical relevance: Which party, in the discussion, carries, or should carry the burden of proof? How should we, in light of that, structure a reasonable discussion? If both parties have standpoints, should they both carry the (equal) burden of proof, or should one party be dialectically privileged? I shall call this the allocation question. In this paper, I deal with the allocation question in those situations where it is a presumption that is challenged, rejected or contradicted.

In the general case, where it is not a presumption that gets challenged, it might seem that there is a simple answer: in the mixed discussion, where both parties have standpoints, we should accept a symmetrical allocation of the burden of proof (van Eemeren and Houtlosser 2002; Walton 2014). This answer coheres well with the so-called dialectical egalitarianism. According to this philosophical tradition, every proposition, if challenged, must be supported by an argument if the parties have previously decided to engage in a reasonable discussion (see Rescorla 2009a). Consequently, there are neither privileged parties nor privileged standpoints: "In a mixed dispute, where two parties have advanced contradictory standpoints, each party has a burden of proof for his own standpoint" (van Eemeren and Houtlosser 2002, p. 18).

Despite their intuitiveness and elegance, ${ }^{2}$ the symmetrical allocation and dialectical egalitarianism are, to some extent, contro-

\footnotetext{
${ }^{1}$ This paper is a revised and extended version of Bodlović (2020a).

2 One aspect of "elegance" is that the allocation question seems to get resolved almost on conceptual grounds. That is, if we must attribute the burden of proof to every party whose position gets challenged (rejected, contradicted) in the dialogue, then allocating the burden of proof comes down to nothing more than rephrasing the definition of the burden of proof: the answer to a question of who carries the burden of proof seems already contained in the meaning of the burden of proof.
}

(C) Petar Bodlović. Informal Logic, Vol. 40, No. 2 (2020), pp. 255-294 
versial. Many philosophers and argumentation scholars argued that sometimes we should accept an asymmetrical allocation of the burden of proof since some propositions are dialectically privileged. Once these "onus-assigning statements" (Brown 1970, p. 74) get rejected, they do not require support until or unless the opponent presents (sufficient) reasons against their acceptability. According to the standard account, privileged propositions which shift, reverse, or asymmetrically allocate the burden of proof, and that are also defeasible in nature, are called presumptions (Whately 1963; Rescher 1977, 2006; Ullmann-Margalit 1983; Cargile 1997; Freeman 2005; Walton 2014; Godden 2017). So, if both parties have standpoints and their standpoints get challenged, then both parties carry the burden of proof unless one standpoint is a presumption.

The standard accounts of presumption are surprisingly heterogeneous (see Godden and Walton 2007; Lewiński 2017) and there are at least two sources of heterogeneity. First, there are fundamental disagreements among scholars on how to characterize presumptions, ${ }^{3}$ and, second, there are fundamental differences between different types of presumptions. For instance, we might distinguish cognitive (epistemic) and practical presumptions since they operate in different dialogical contexts (epistemic inquiry $v s$. practical deliberation), perform distinct normative functions (promoting epistemic vs. non-epistemic goals) and, thereby, have qualitatively different foundations (Ullmann-Margalit 1983, p. 143; Rescher 2006, p. 27; Godden and Walton 2007, p. 337; Lewiński 2017, p. 610). ${ }^{4}$

\footnotetext{
${ }^{3}$ For instance, scholars disagree whether presumptions are rules (Prakken and Sartor 2006) or propositions (Walton 2014); statuses, modifiers, qualifiers of propositions (Godden 2017, 2019) or relations (Pinto, according to Freeman 2005, p. 27); based on inferential (Godden and Walton 2007) or discursive support (Freeman 2005; Rescher 2006); and whether they belong to the opening (van Eemeren and Houtlosser 2002) or the argumentation stage of the critical discussion (Walton 2014).

${ }^{4}$ Importantly, the proposed distinction is also a matter of controversy. Some scholars believe that we should, indeed, distinguish practical from cognitive presumptions (e.g., Rescher 2006, Freeman 2005), and others remain open to this possibility (e.g., Ullmann-Margalit 1983, p. 143; Godden and Walton 2007, p. 337). However, Godden (2019) has recently argued against the theoretical (C) Petar Bodlović. Informal Logic, Vol. 40, No. 2 (2020), pp. 255-294
} 
Cognitive presumptions are typically used in the context of inquiry. In a reasonable epistemic discussion about the shape of Earth, "The Earth is globe-shaped" is a (strong) cognitive presumption since this proposition "represents our most plausible candidate for truth" (Rescher 2006, p. 71). The dialogical parties should recognize that, due to the overwhelming and well-known (scientific) evidence that the Earth is globe-shaped, "The Earth is globe-shaped" should be exempted from the standard burden of proof, i.e., that the burden of proof should rest only with its opponent. The concept of a cognitive presumption coheres well with dialectical foundationalism, a philosophical tradition which suggests that the rules of reasonable discussion should protect (epistemically) uncontroversial propositions and sanction (epistemically) deviant challenges (Rescorla 2009a). By contrast, practical presumptions are typically used in the context of practical deliberation. In criminal law, for instance, "John is innocent" is a (strong) practical presumption: since we should "try to minimize the conviction of innocent persons, even at the cost of letting guilty persons go free" (Walton 1988, p. 244) the (global) burden of proof rests only with the prosecutor, and "John is innocent" stands good until or unless the prosecutor proves otherwise. Although inspired by legal scholarship, the concept of a practical presumption is readily applicable to many everyday contexts where, in the circumstances of uncertainty and pressure to make a timely decision we wish to avoid more significant harm (see Ullmann-Margalit 1983; Godden 2017).

Cognitive and practical presumptions are different in many respects, ${ }^{5}$ but one feature seems to hold them together. According to

relevance of cognitive (epistemic) presumptions and insisted that "presumably" is exclusively a practical (non-epistemic) modality. Although he presents plausible concerns about the notion of cognitive presumption, this paper sets these concerns aside and assumes that cognitive presumptions represent a legitimate class of presumptions.

5 Not only do cognitive and practical presumptions have different ultimate contextual functions (i.e., acquiring truths vs. making right decisions) and different normative functions (promoting epistemic vs. non-epistemic goals), but they also have distinct dialogical functions (i.e., practical presumptions do not stop dialectical regress); pragmatic functions (i.e., two types of presumptions usually do not avoid greater harm in the same sense); and, at least some(C) Petar Bodlović. Informal Logic, Vol. 40, No. 2 (2020), pp. 255-294 
the standard accounts, regardless of whether $p$ is a cognitive or a practical presumption, if $p$ gets rejected, then the burden of proof rests exclusively with the opponent. Hence, all presumptions share the same deontic function: they asymmetrically allocate the burden of proof. The idea of asymmetrical allocation is a cornerstone of the standard account of presumptions for two reasons: first, all types of presumptions, supposedly, share this function (despite other differences), and, second, all traditional scholars seem to agree on this idea (despite other disagreements).

In this paper, I will explore the deontic function of presumptions in some detail and (provisionally) answer the allocation question in so-far as presumptions are concerned. The main question is the following: What, exactly, does the deontic function of presumption amount to? Once presumptions are rejected, do they immediately place the burden of proof on the opponents? If they do, what, exactly, does the burden of proof amount to; and, if they do not, what other obligations might be relevant? Do presumptions place the burden of arguing, the burden of explanation, or the most general burden of reasoning on their opponents? And how do obligations to provide arguments, explanations, or reasons (of whatever kind) connect to the burden of proof?

Minimally, the paper shows that the standard account of the deontic function is ambiguous. If presumptions allocate the burden of proof on the opponent, then they allocate it in two distinct senses: cognitive presumptions allocate a general burden of reasoning (the opponents are obliged to produce any kind of reason), and practical presumptions allocate a more specific burden of arguing (i.e., the opponents are obliged to produce dialectically adequate reasons). Nevertheless, the standard account is not only ambiguous but also implausible: since burden of proof is best understood as a burden of arguing (rather than the burden of reasoning which includes the burden of explanation) cognitive presumptions, strictly taken, do not asymmetrically allocate the burden of proof. Consequently, the standard accounts require clarifications and, most probably, revisions.

times, they seem susceptible to different types of defeaters. For details, see Bodlović (2020b, forthcoming).

(C) Petar Bodlović. Informal Logic, Vol. 40, No. 2 (2020), pp. 255-294 
To be sure, some scholars have already claimed that the standard accounts of presumption, as well as dialectical foundationalism, are not plausible. For instance, Kauffeld (1998, 2003, 2005) and Bermejo-Luque (2019) argued that, in the context of everyday dialogue, presumptions are not always negatively correlated to the burden of proof, and dialectical egalitarians insist that a reasonable discussion should never be dogmatic (Rescorla 2009a, p. 96). This paper adds to this trend by distinguishing between various types of presumptions and distinct possible meanings of burden of proof, and answers the more refined allocation questions generated by the increase in typological and conceptual detail. For the most part, the paper hopes to enhance the study of presumptions by adding to the analytic sophistication.

I first outline common principles of asymmetrical allocation (Sect. 2), and then focus on the cognitive and practical presumptions (Sect. 3). In Sect. 4, I deal with the different possible meanings of the burden of proof (the burden of reasoning, and the burden of arguing) and their relationships to the burden of explanation. After explaining these notions, I connect them to cognitive and practical presumptions (Sect. 4.1-4.4). In conclusion, I provide a summary of the most important results.

\section{Common principles of asymmetrical allocation}

The idea that, sometimes, only one dialogical party must provide reasons when both parties have standpoints is present in both ordinary and academic contexts. For instance, when the journalist challenged Donald Trump's suspicions about potential voter fraud, Trump refused to support his view; instead, he complained that journalist did not provide evidence that fraud did not happen. So, it seems that Trump implicitly appealed to the asymmetrical allocation of the burden of proof (for details, see CNBC.com staff 2016).

In academic contexts, appeals to the asymmetrical allocation are often more explicit. It is "a piece of scientific orthodoxy" (Dare and Kingsbury 2008, p. 511) that the burden of proof should exclusively rest with those who propose new scientific hypotheses, theories, or paradigms. Asymmetrical allocation is also advocated 
by philosophers. In a metaphysical discussion about the relationship between free will and determinism, Lycan (2003) argues that only the proponents of incompatibilism should carry the burden of proof. In the discussion about the existence of God, Pascal (2004) suggests that the burden of proof should rest with the atheist ("Pascal's wager"), whereas Scriven (1966), and Flew (1972) argue that the atheist should have a presumption in her favour. In epistemology, an asymmetrical allocation is relevant for regulating the debate between a sceptic and a dogmatist (Brown 1970; Kelly 2005), and for resolving a problem of infinite (dialectical) regress (see Rescher 1977; Rescorla 2009b). Also, it is present in the ethical debates about discrimination and global justice (Räikkä 1997; 2005), organ markets, human enhancement, climate change, and the precautionary principle (Koplin and Selgelid 2015). Finally, in metaphilosophy, Williamson (2011) argues that the burden of proof should rest with those who deny that philosophical expertise contributes to the successful performance of thought experiments. Therefore, the asymmetrical allocation has been advocated by a number of scholars, across many disciplines and within different intellectual traditions.

The asymmetrical allocation of the burden of proof can be "merely a labor-saving device" (Brown 1970, p. 74), a trick used to achieve an unfair dialogical advantage (as in the Trump example). Yet, asymmetrical allocations can have procedural, prudential, epistemic, or even moral foundations that generate various principles. In my view, we can divide the common principles of asymmetrical allocation (which are not motivated exclusively by rhetorical self-interest) into two broad categories: propositionrelated principles and agent-related principles. In the remainder of this section, I present some well-known principles and explain the proposed categorization.

Let us focus on the popular slogan "she who asserts must prove." Although this "overarching principle of burden of proof" (Walton 2014, p. 99) appears straightforward, it is ambiguous for (at least) two reasons. First, it is unclear whether "she who asserts must prove" is the principle of symmetrical or asymmetrical allocation. On the one hand, if we understand the principle literally and apply it to a mixed discussion, then the principle allocates the 
burden of proof symmetrically: both parties are obliged to provide reasons because both parties assert standpoints. On the other hand, it seems that "she who asserts must prove" is, at least sometimes, understood as the principle of asymmetrical allocation. The literature allows several (incompatible) explanations of why this might be the case, which, in turn, render the overarching principle even more ambiguous. As a result, not only is it unclear whether the overarching principle symmetrically or asymmetrically allocates the burden of proof but also it is unclear on what grounds, exactly, this principle is supposed to allocate the burden of proof asymmetrically.

There are (at least) three interpretations of "she who asserts must prove" that would allow the overarching principle to allocate the burden of proof asymmetrically in a mixed discussion. First, the act of making an assertion is sometimes understood as the act of "bringing the action" or initiating an argument. Under this interpretation, the overarching principle would mean that (1) the burden of proof rests (only) with the dialogical party who presents the view first, rather than with anyone who performs the speech act of an assertion: "Whichever side initiates the assertion of a thesis within the dialectical situation has the burden of supporting it in argument" (Rescher 2006, p. 15). ${ }^{6}$ Second, the act of making an assertion is sometimes understood as the act of challenging accepted practices, values, or beliefs, i.e., the act of rejecting the status quo. Under this interpretation, the overarching principle would mean that (2) the burden of proof rests (only) with the party who asserts something (dialectically, epistemically, instrumentally) controversial (see Räikkä 1997, pp. 466-467). ${ }^{7}$ Third, it seems that asserting is sometimes understood as "affirming." On this interpretation, the overarching principle would mean that (3) the burden of proof rests (only) with the party who asserts a positive claim (Cargile 1997, p. 61). ${ }^{8}$ For the most part, the previous inter-

\footnotetext{
${ }^{6}$ This is connected to the legal principle: Semper necessitas probandi incumbit ei qui agit.

${ }^{7}$ Since somebody can initiate a discussion without asserting a highly controversial claim, these principles are logically independent.

${ }^{8}$ The principle "affirmati non neganti incumbit probatio" rests on the idea that it is not dialectically reasonable to allocate the burden of proof on the proponent (C) Petar Bodlović. Informal Logic, Vol. 40, No. 2 (2020), pp. 255-294
} 
pretations are concerned with the question: How should we allocate the burden of proof given what we know about the (normatively) relevant properties of the standpoints or claims (i.e., is the claim presented first, is it controversial, and is it an affirmation or a negation)? As a result, three interpretations of the overarching principle represent proposition-based principles of asymmetrical allocation. ${ }^{9}$

The second group of principles is concerned with a different question, namely: How should we allocate the burden of proof (in order to facilitate the optimal resolution) given what we know about the dialectically relevant abilities or inclinations of dialogical parties? Consider the case where David says to Luke: "Well, I paid the last round of drinks; so, it is your turn!" Since it is Luke who paid the last round, he disagrees with David, and the discussion begins. But suppose that Luke has a receipt in his pocket. In this case, although David initiates the conversation and advances a controversial claim, ${ }^{10}$ the resolution procedure will be more effective if Luke incurs the burden of proof. Luke has access to deci-

of the negative claim because it is demanding to prove the absence of property, fact or incident. The usual explanation, however, is even stronger because it suggests that it is impossible to prove a negative claim: "You cannot prove a negative." This slogan is typically applied in the discussions about the existence of paranormal or supernatural entities (such as God) and is "combined with the thought that people should not be assigned obligations to do impossible things" (Cargile 1997, p. 61). Nevertheless, scholars have argued that, in the usual circumstances, it is possible to prove a negative claim (Cargile 1997; Macagno and Walton 2011; Pigliucci and Boudry 2014) and that even if proving a negative claim is more demanding, it should not affect the allocation of the burden of proof. For instance, according to the "priority principle," the negative assertion should only affect the order of defense: both parties should have the burden of proof, but the proponent of the positive claim should go first (van Eemeren and Houtlosser 2002).

9 One could argue that the previous allocation principles do not represent different interpretations of "she who asserts must prove." Instead, they represent independent principles that show that the overarching principle is defeasible. On this view, "she who asserts must prove" is a default principle which can be overridden by more specific considerations: the dialogical party should support her assertion unless (1) she did not initiate a discussion, (2) her assertion is uncontroversial, or (3) she asserted a negation. This alternative proposal would render the overarching principle less ambiguous.

${ }^{10}$ Suppose, for instance, that all other friends saw who paid the drinks.

(C) Petar Bodlović. Informal Logic, Vol. 40, No. 2 (2020), pp. 255-294 
sive evidence, and should he be obliged to present it, the issue would be quickly resolved. The principle, therefore, is the following: (4) the burden of proof rests (only) with the party who has better epistemic access to evidence. ${ }^{11}$

Finally, suppose that David wants to buy a car from Luke. In this case, it is crucial to determine whether the vehicle is in good condition, and Luke, as a longtime owner, surely has better access to evidence. However, since Luke's motivation to speak truthfully might be compromised, it is useful to attribute the burden of proof to David, who has a genuine interest in discovering the truth. If the primary goal is to acquire true belief about the car's condition, then asymmetrical allocation might, once again, facilitate the optimal resolution of the issue (see Dare and Kingsbury 2008). ${ }^{12}$ Hence, the underlying principle is the following: (5) the burden of proof rests (only) with the party who is less biased, or who does not have corrupted motivation. Notice that the last two principles are not concerned with the properties of propositions but rather with distinctive abilities or inclinations of dialogical parties. (i.e.,

${ }^{11}$ In civil law, this is known as the "principle of fairness" (van Eemeren et al. 2002, p. 115) and it is usually applied in the cases of product liability (Hahn and Oaksford 2007, p. 41).

12 This is linked to the legal principle caveat emptor (Dare and Kingsbury 2008). The proposed list is not exhaustive. For instance, Hansen (2019) mentions two additional principles: the burden of proof "belongs to the party who would lose the case if the outcome had to be decided at this point," and "it belongs where the law says it belongs" (pp. 15-16). In addition, we can refine the studies of asymmetrical allocation by taking into account the pragmatic dimensions of propositions. In other words, we should not focus only on the party who introduces the proposition (e.g., is it the party who 'brings the action,' or with 'pure motivation'?) and the nature of proposition (e.g., is it a negative one, or controversial one?), but also on the (intended) pragmatic goal that underlies the proposition. Along these lines, Kauffeld suggests that the allocation of the burden of proof depends (1) on the type of speech act. Thus, $p$ will entail the burden of proof if used as a proposal, but not if used as a suggestion (Kauffeld 1998). Pragma-dialecticians also recognize the importance of pragmatic properties. In their opinion, however, what determines the allocation is, strictly speaking, not the nature of the particular speech act, but (2) the argumentative function of this speech act in a critical discussion (Tseronis 2009, p. 83). Thus, some suggestion $p$ will entail the burden of proof if it represents a (sub)standpoint, but not if it represents a starting point accepted at the opening stage.

(C) Petar Bodlović. Informal Logic, Vol. 40, No. 2 (2020), pp. 255-294 
the ability to provide sufficient proof, and the inclination towards truth). As a result, they represent agent-based principles of asymmetrical allocation.

In the following sections, I will mostly focus on the second proposition-based principle mentioned above. According to this principle, some propositions do not require support because, in some contexts and circumstances, they seem epistemically plausible or instrumentally desirable. Typically, these propositions are called cognitive and practical presumptions. Although one may propose that all aforementioned principles "explicitly or implicitly determine, at least partly, what it is reasonable or justified to presume" (Räikkä 1997 p. 463), the analysis in this paper will start from a somewhat narrower concept of presumption.

\section{Cognitive and practical presumptions}

Suppose that Diane and Steve are discussing the shape of the Earth. Diane admits that scientific claims are defeasible, but believes that science offers the best available answers about the natural world. In this specific epistemic dialogue, Diane claims that the Earth is globe-shaped (spherical) and readily accepts this belief as her standpoint. By contrast, Steve is a member of the Flat Earth Society, who believes that the overwhelming scientific evidence is a fabrication. He thinks that the Earth is disc-shaped, and accepts this belief as his standpoint.

In the ordinary context, "The Earth is globe-shaped" is a (strong) cognitive presumption. Since this empirical claim is, in principle, defeasible, it could be reasonable to discuss it and, in exceptional circumstances, even reject it. ${ }^{13}$ In the normal cases, however, any reasonable person (with primary education) should nowadays acknowledge that, in Rescher's words, "The Earth is globe-shaped" is "our most plausible candidate for truth" (2006, p.

\footnotetext{
13 "The Earth is globe-shaped" is defeasible in the sense that it not with mathematical certainty that the proposition is true, and it is conceptually possible that some day we obtain information that would show it to be false. So, it is not, in principle, irrational either to have a discussion about it or to reject it.
}

(C) Petar Bodlović. Informal Logic, Vol. 40, No. 2 (2020), pp. 255-294 
71). Many reliable epistemic sources vouch for it, ${ }^{14}$ and this fact requires dialectical recognition: in epistemic dialogue, the proponent of a plausible standpoint and the proponent of an implausible standpoint should not play by the same rules. Granted, the dialectical rules should not require an immediate acceptance of the most plausible standpoint, but, also, they should not force us to proceed as if, initially, all propositions are equally plausible. Epistemic dialogues must avoid both uncritical dogmatism and naïve egalitarianism: on the one hand, its rules must allow the criticism of plausible standpoints (since this is a desirable epistemic attitude) but, on the other hand, give some dialectical credit to (highly) plausible standpoints (since, initially, they seem epistemically warranted).

If we must regulate epistemic dialogues by dialectical rules that systematically further epistemic ends, then the asymmetrical allocation of the burden of proof seems like a proper regulatory choice. In the Flat Earth example, the acceptance of "The Earth is globe-shaped" appears to facilitate the acquisition of true or justified beliefs, so Diane should not carry the burden of proof. By contrast, initially, the acceptance of "The Earth is disc-shaped" appears to get in the way of achieving epistemic goals, and, for this reason, Steve should carry the burden of proof. ${ }^{15}$ This means that Steve should show that circumstances are somehow exceptional, and present (persuasive) arguments that the Earth is discshaped. ${ }^{16}$ If his arguments, ultimately, do not survive Diane's

\footnotetext{
14 For instance, scientific authority, evidence, testimonies, and explanatory utility.

${ }^{15}$ Not only is this view supposed to cohere with some pre-theoretical intuitions (Rescorla 2009a), but it also seeks to resolve a well-known theoretical problem of an infinite (dialectical) regress (see Rescher 1977; Freeman 2005; Rescorla 2009b).

${ }^{16}$ It is crucial to notice that Steve is obliged to present (persuasive) arguments that the Earth is disc-shaped in order to win the discussion, but not in order to defeat the presumptive status of "The Earth is globe-shaped." The presumptive status of Diane's standpoint gets defeated as soon as Diane incurs the regular burden of proof, i.e., becomes obliged to argue that the Earth is globe-shaped. In principle, Steve can make this happen by successfully undercutting wellknown scientific evidence and, thereby, showing that "The Earth is discshaped" and "The Earth is globe-shaped" are equally plausible propositions. In (C) Petar Bodlović. Informal Logic, Vol. 40, No. 2 (2020), pp. 255-294
} 
critical testing, "The Earth is globe-shaped" gets accepted by default. ${ }^{17}$ So, initially, an asymmetrical allocation favors the more plausible propositions and sanctions deviant challenges, but it still allows the criticism of credible claims and offers a normative infrastructure for having a debate about widely-accepted views that happen to be controverted by eccentric individuals.

One may wonder whether a member of a Flat Earth Society is committed to the evidence that, supposedly, makes "The Earth is globe-shaped" a cognitive presumption. If Steve finds (scientific) evidence inadequate to begin with, then it is unclear whether "Steve actually rejects a presumption, rather than Diane's assertion of the presumptive status" (Godden 2020, p. 5). This leads us to a fundamental question: Can $p$ have a presumptive status in a particular dialogue $D$ even when reasons $R$ that vouch for $p$ (i.e., make $p$ the most plausible proposition) are not conceded by parties in $D$, i.e., are not dialectically adequate in $D$ ? In standard theories of cognitive presumption, dialectical adequacy of $R$ does not seem necessary for $p$ 's presumptive status. There are at least two reasons. First, if the dialectical adequacy of $R$ were necessary, then, at some point in the dialogue, the opponent could defeat presumption by making $R$ inadequate: the opponent could simply retract her commitment to (previously conceded) reasons $R$ and, by doing this, defeat $p$ 's presumptive status. On the standard accounts, however, this is not enough: to defeat $p$ 's presumptive status, the opponent must offer reasons (and not only retract some). Second, it seems that the opponent could be committed to presumption because of the broader cultural context and, in some sense, intellectual humility. That is, even if Steve neither concedes $R$ nor

this case, "The Earth is globe-shaped" ceases to be the most plausible truthcandidate, but Steve does not win the discussion by defeating a presumptive status in the described fashion. Instead, he only resets the discussion: from that point on, Diane also incurs the burden of proof, and the dialogue continues in a new normative setting.

17 This dialectical bias towards a scientific status quo is generally relevant for regulating a debate between scientists and pseudoscientists. According to Pigliucci and Boudry (2014), since pseudoscientific claims (concerning, e.g., Intelligent Design, extraterrestrial visits, anti-vaccination, or the denial of an anthropogenic climate change) have low prior probabilities, their proponents should carry the burden of proof.

(C) Petar Bodlović. Informal Logic, Vol. 40, No. 2 (2020), pp. 255-294 
recognizes its force, he should still recognize that, in the relevant cultural context, $R$ and the presumptive status of "The Earth is globe-shaped" are accepted by the (more or less) equally competent majority. So, even if Steve rejects the adequacy of these reasons and doubts their plausibility, he must still recognize their legitimacy. The further investigation of the relationship and normative significance of plausibility, adequacy, and legitimacy, unfortunately, falls outside the scope of the present paper.

To sum up, on the standard view, if $p$ is the most plausible truth-candidate in inquiry, then $p$ is a dialogically privileged proposition and represents a cognitive presumption. So, the status of cognitive presumption is both an epistemic status, as well as a dialogical status of a proposition.

Next, suppose that Mark and Alice are discussing whether to attend their friend's house party. They are invited and would, generally, like to go, but their decision (mostly) depends on whether John will be at the party. John is a person whom Mark and Alice intensely dislike, and they agree that his presence will necessarily ruin their evening. ${ }^{18}$ Since the chance that John will be at the party is, roughly, a half, Mark and Alice are facing the socalled "deliberation problem" (Ullmann-Margalit 1983, p. 152; Godden 2017, p. 505): since the party is about to begin, they must make their decision quickly; but since John's whereabouts are uncertain, they cannot base their decision on a justified belief. Let us suppose that, in the described circumstances, Mark decides to proceed as if John will be at the party, and makes the following proposal: "We should skip the party." Alice, however, replies: "We should go to the party."

In the Party example, "John will be at the party" is a practical presumption. Scholars typically characterize practical presumptions as propositions that we proceed upon (or take as true) when there is pressure to make a timely decision and the evidence is uncertain (Ullmann-Margalit 1983; Walton 2014; Godden 2017).

\footnotetext{
${ }^{18}$ For the sake of example, imagine that Mark and Alice have objective reasons to hate John, and that, due to these reasons, John is definitely the last person they would like to see, let alone to party with. For instance, just some months ago John has seriously injured their daughter in a car accident while driving drunk and has never apologized.
}

(C) Petar Bodlović. Informal Logic, Vol. 40, No. 2 (2020), pp. 255-294 
In these special circumstances, the main goal is to make a decision that avoids more significant harm. Accordingly, "John will be at the party" is a practical presumption because (1) there is a pressure to decide whether to go on the party; (2) this decision depends on whether John will be at the party; (3) it is uncertain whether John will be at the party; but (4) parties agree that proceeding on "John will be at the party" and skipping it (when, in fact, John will not be there) seems like a lesser evil than proceeding on "John will not be at the party" and attending it (when, in fact, John will be there). ${ }^{19}$ Since proceeding on "John will be at the party" seems more desirable in the described circumstances, and both Mark and Alice agree that it is more desirable, the distribution of dialectical obligations should not be (completely) symmetrical.

In a deliberation dialogue, the asymmetrical allocation of a burden of proof is a reasonable regulatory choice to promote the goal of avoiding greater harm. Since proceeding on "John will be at the party" promotes this goal in the Party case, Mark should not carry the burden of proof: in the circumstances of pressure and uncertainty, his position should be a dialogically privileged presumption. By contrast, proceeding on "John will not be at the party" potentially gets in the way of avoiding greater harm and, for this reason, Alice must carry the burden of proof. This means that Alice must provide arguments against presumption, and if her arguments, ultimately, cannot persuade Mark to go to the party, ${ }^{20}$ "We should skip the party" gets accepted by default. Dialogical parties should not carry equal dialogical obligations since, in the described circumstances, their practical standpoints are not equally desirable.

\footnotetext{
${ }^{19}$ Notice that this everyday example is closely similar to the legal presumption of innocence. Here, "John is innocent" has a status of practical presumption since (1) there is a legal pressure to decide whether to convict John; (2) this decision depends on whether John is innocent or guilty; (3) it is evidentially uncertain whether John is innocent or guilty; but (4) acting as if John is innocent and letting him free (when, in fact, John is guilty) is treated as a lesser evil than acting as if John is guilty and convicting him (when, in fact, John is innocent).

${ }^{20}$ She must prove that it is more likely that John will skip the party by using dialectically adequate reasons, i.e., reasons that Mark is expected to accept.

(C) Petar Bodlović. Informal Logic, Vol. 40, No. 2 (2020), pp. 255-294
} 
In summary, if proceeding on $p$ is the most desirable practical alternative in deliberation, then $p$ is a dialogically privileged proposition and represents a practical presumption. So, the status of a practical presumption is both a practical status, as well as a dialogical status of a proposition. ${ }^{21}$ In the next section, I explore the dialogical status by carefully examining the deontic functions of cognitive and practical presumptions.

\section{Presumptions and different conceptions of the burden of proof}

The idea that presumption is "closely connected to the burden of proof" (Walton 2014, p. 117) lies at the heart of every standard account of presumption. According to Rescher's account, for instance, presumption and burden of proof "represent correlative conceptions" (2006, p. 14) and are "opposite sides of the same coin" (2006, p. 14). Freeman seems to agree with this characterization since, according to his account, presumption is "the opposite of burden of proof" (2005, p. ix). But what, exactly, does this mean in the discussion where two parties take turns? Let us begin with some clues from the literature.

[A] 'Presumption' in favour of any supposition ... implies that it must stand good till some sufficient reason is adduced against it; in short, that the Burden of proof lies on the side of him who would dispute it. (Whately 1963, p. 112).

[W] here a proposition has the status of a presumption, then the burden of proof lies with anyone who refuses to concede it. (Pinto 2001, p. 4).

$[\mathrm{P}]$ resumption is defined as a modal status (or property) of a claim (or proposition) indicating that the burden of proof with respect to that claim rests with anyone who would reject it. (Godden and Walton 2007, p. 315)

21 For a detailed characterization of practical presumptions, see UllmannMargalit (1983), Godden (2017), and Bodlović (2020b, forthcoming).

(C) Petar Bodlović. Informal Logic, Vol. 40, No. 2 (2020), pp. 255-294 
The presumption shifts a burden [of proof] to the other side to disprove it, or the proposition becomes lodged into place as a commitment of both sides. (Walton 2014, p. 117)

[T]he presumption opponent is charged with something: with the burden of showing that not-q. (Ullmann-Margalit 1983, p. 151)

Setting subtle differences aside, ${ }^{22}$ standard accounts appear to accept the following idea: If the proponent $P$ puts forward $p$ (that in the context at hand has the status of a presumption) in turn $t_{l}$, and the opponent $O$ rejects or challenges $p$ in turn $t_{2}$, then $P$ does not carry the burden of proof in $t_{3}$ whereas $O$ incurs the burden of proof in ( $O$ 's next turn) $t_{2}+n$. I shall call this an asymmetrical allocation of the burden of proof.

The next question is: Is the asymmetrical allocation unconditional, or is it conditional on the proponent's request for reasons? In other words, does the opponent $O$ incur the burden of proof in turn $t_{3}$, immediately after rejecting the presumption in $t_{2}$ ? Or does $O$ incur the burden in turn $t_{4}$, after the proponent $P$ activates $O$ 's burden by requesting reasons in $t_{3}$ ? Does turn $t_{2+n}$ amount to $t_{3}$ or $t_{4}$ ?
( $\left.t_{1}\right) P$ : Presumably, $p$.
( $\left.t_{2}\right) O$ : Reject: "Presumably, $p . "$
$\left(t_{3}\right)$ ?
$\left(t_{4}\right)$ ?

Although I do not discuss this issue in the present paper, notice that previous citations say nothing about the active role of the proponent in allocating the burden of proof. $O$ appears to incur the burden of proof by merely disputing, rejecting, or refusing to concede the presumption. This could indicate, at least to some degree, that, on standard accounts, the asymmetrical allocation is supposed to be immediate: by rejecting the presumption in $t_{2}, O$ incurs the burden of proof in the next turn $t 3$, and, $O$ 's burden is

\footnotetext{
22 That every presumption "implies" or "indicates" that the opponent who rejects it carries the burden of proof does not necessarily mean that every presumption "shifts" the burden of proof.

(C) Petar Bodlović. Informal Logic, Vol. 40, No. 2 (2020), pp. 255-294
} 
not conditional on P's request for reasons. I call this an unconditional allocation of the burden of proof and propose the following specification of the deontic function.

THE STANDARD DEONTIC FUNCTION OF PRESUMPTION: Presumptions (1) allocate (2) the burden of proof in an (3) unconditional and (4) asymmetrical manner.

To fully understand the standard deontic function of presumption, we should specify the meanings of four complicated notions: allocation, burden of proof, unconditional (allocation), and asymmetrical (allocation). In this paper, I focus on the notion of the burden of proof and seek to provide a preliminary conceptual analysis. This is a surprisingly demanding task. Although we use the term burden of proof casually in ordinary parlance, it is complicated to determine its precise meaning. In legal scholarship, for instance, Thayer maintains that the burden of proof is an ambiguous notion that needs to be thoroughly explored and discriminated (2019, p. 75), and McCormick describes it as "the slipperiest member of the family of legal terms" (Strong 1992, p. 449). It is hardly surprising that as "the most successful jurisprudential 'export" (Hahn and Oaksford 2007, p. 40), the term retains its complexity in philosophy and argumentation theory.

In the following (sub)sections, I offer two interpretations of the burden of proof and analyse whether cognitive and practical presumptions, under these different interpretations, place the burden of proof on the opponents.

\subsection{Presumptions, and the burden of reasoning}

Let us begin with the underlying core idea that everyone accepts. According to a "first approximation, having a burden of proof is being under an obligation ... to support one's view" (Aijaz et al. 2013, p. 260) or "furnish support for the thesis" (Johnson 2000, p. 194). Since the burden of proof naturally belongs to a context of dialogue (Rescher 2006, p. 19) and in this context to support means to provide reasons, the burden of proof can be understood as an obligation to "provide reason" (Kauffeld 1998, p. 263) or 
“present some reasons" (Räikkä 1997, p. 467). ${ }^{23}$ This very general interpretation of the burden of proof, I label the burden of reasoning $(B o R)$ :

THE BURDEN OF REASONING (BoR) is the party's dialogical obligation to provide any reason (either dialectically adequate or inadequate) for a position (view).

What does interpretation of the burden of proof in terms of $B o R$ mean for the deontic function of presumption? Well, it means that, after rejecting presumption, the opponent is obliged to provide some reason for her position. Two points must be made here. First, at first sight, this result appears consistent with the standard accounts since no standard account will deny that, after rejecting a presumption, the opponent must provide reasons. Second, this interpretation of the deontic function preserves the deontic similarity between cognitive and practical presumptions. That is, regardless of whether the proposition is epistemically plausible ("Presumably, the Earth is globe-shaped"), or desirable to proceed on for non-epistemic reasons ("Presumably, John will be at the party"), the opponent must provide reasons after rejecting it.

( $\left.t_{1}\right) P$ : Presumably, $p$.

( $\left.t_{2}\right)$ O: Reject: "Presumably, $p . "$

(t3) O: Reason: $r$. [discharging the $B o R$ ]

If the $B o R$ expresses the core idea that underlies the burden of proof, appears consistent with the standard characterization of deontic function, and preserves the similarity between two types of presumption, ${ }^{24}$ why shouldn't we define the burden of proof in terms of $B o R$ and conclude our analysis at this point? The answer is twofold. First, the less general conception of the burden of proof is more analytically useful since it opens essential theoretical

\footnotetext{
${ }^{23}$ Though the core idea is uncontroversial, to interpret the burden of proof as requiring nothing more specific than reasons happens to be controversial, as we shall see below. So, that everybody accepts the general, core idea means that accepting this idea is necessary for accepting any other, accurate, more specific interpretation of burden of proof: the more precise interpretations imply or presuppose this broader, core characterization.

${ }^{24}$ Contributing, thereby, to the overall coherency of standard accounts.

(C) Petar Bodlović. Informal Logic, Vol. 40, No. 2 (2020), pp. 255-294
} 
questions and reveals differences between cognitive and practical presumptions. Second, philosophers and argumentation scholars (traditional theorists of presumptions included) typically adopt a less general conception. So, what exactly do they mean by this less general conception of the burden of proof?

\subsection{Presumptions, and the burden of arguing}

Let us focus on the obligation to provide a reason, i.e., on the burden of reasoning. This general dialectical obligation includes distinct sub-obligations, most notably the obligation to provide an argument, and the obligation to provide an explanation. Philosophers and argumentation scholars, however, typically contend that "[t]o have the burden of proof is to be rationally required to argue for or provide evidence for your position" (Dare and Kingsbury 2008, p. 503). In other words, the burden of proof is an obligation of an "arguer" (Johnson 2000, p. 194) to "argue" (van Eemeren and Houtlosser 2002, pp. 17) or present "arguments" (Walton 1988, p. 234; Freeman 2005, p. ix; Govier 2010, p. 175; van Laar and Krabbe 2013, p. 202). On this interpretation, the burden of proof is not just the burden of reasoning but, more accurately, the burden of arguing $(B O A)$.

THE BURDEN OF ARGUING $(B o A)$ is the party's dialogical obligation to provide a dialectically adequate, argumentative reason for a position (view).

To understand the nature of $B o A$, we must know that the paradigmatic goal of arguing is to persuade the other party (Walton 1990; Blair 2012) or to resolve the difference of opinion (van Eemeren and Grootendorst 2004). To achieve this goal, an arguer should offer reasons that the other party, ideally, has already conceded (van Laar and Krabbe 2013, p. 212) or will most likely concede. ${ }^{25}$ I shall call these reasons argumentative reasons. In effect, the burden of arguing is an obligation to provide reasons acceptable to the other party (typically) for the sake of persuading her.

\footnotetext{
${ }^{25}$ Scholars refer to this requirement by using different notions, such as "premise acceptability" (Johnson 2000, p. 194; Govier 2010, p. 87), or "premise adequacy" (Goodwin 2001, p. 2).

(C) Petar Bodlović. Informal Logic, Vol. 40, No. 2 (2020), pp. 255-294
} 
What does this mean for the deontic function of presumptions? Are presumptions supposed to place the burden of arguing on the opponent's side? According to standard accounts, they are. Traditional theorists contend that the opponent must "disprove the proposition in question" (Walton 2014, p. 274), adduce "sufficient reason ... against it" (Whatley 1963, p. 112), or "[show] that notq" (Ullmann-Margalit 1983, p. 151). In dialogical contexts, however, the opponent can hardly achieve these goals by (only) explaining her rejection. Rather, to disprove, defeat, or rebut a presumed proposition, the opponent must present "an argument against it" (Pinto 2001, p. 4) or adduce "appropriately weighty counterarguments" (Rescher 2006, p. 16). Supposedly, cognitive and practical presumptions are the same in this respect: on the standard accounts, the opponent is obliged to provide an argument regardless of whether she rejects "Presumably, the Earth is globeshaped" or "Presumably, John will be at the party."

( $\left.t_{1}\right) P$ : Presumably, $p$.

$\left(t_{2}\right) O$ : Reject: "Presumably, $p . "$

( $\left.t_{3}\right)$ O: Argumentative reason: $a$. [discharging the BoA.]

To understand why standard accounts require qualifications, let us start by analysing the deontic function of cognitive presumptions. Is the opponent indeed obliged to present an argument in $t_{3}$, immediately after rejecting cognitive presumption? In the context of an epistemic dialogue, it seems rather doubtful that the opponent must immediately aim at persuasion and present a reason that is acceptable to the proponent. In the Flat Earth example, Steve might (also) be allowed to offer an explanation after rejecting Diane's standpoint "Presumably, the Earth is globe-shaped," i.e., he might be allowed to discharge the burden of reasoning (also) by satisfying the burden of explanation (Rescorla 2009a; van Laar and Krabbe 2013). Why is this so? And what, exactly, is the burden of explanation?

\subsection{Cognitive presumptions, and the burden of explanation}

To understand the nature of the burden of explanation, something must be clear: since Diane and Steve decided to participate in a discussion about the shape of Earth, both should have obligations 
to provide arguments. For instance, Diane has the burden of arguing throughout a debate because she must make objections and cast doubt on Steve's standpoint and arguments. ${ }^{26}$ However, since Diane can (successfully) discharge this burden only by presenting reasons acceptable to her opponent, Steve's rejection of "Presumably, the Earth is globe-shaped" puts her in a difficult position. Which reasons can she possibly use? If Steve rejects a proposition that, in normal circumstances, everyone in their right mind concedes, if the well-known evidence is inadequate to persuade him that the Earth is globe-shaped, then what kind of reason can convince Steve of anything regarding this matter? Steve has shaken the very foundations of reasonable dialogue without providing any guidance on what grounds to continue. Without this kind of guidance, Diane will probably be unable to construct a persuasive argument.

In the Flat Earth example, Diane is facing a complex problem. On the one hand, she cannot use many plausible, well-known, and widely-accepted reasons since they are dialectically inadequate (Steve implicitly rejects them by rejecting "The Earth is globeshaped"). On the other hand, Diane cannot easily anticipate which reasons are dialectically adequate: since Steve seems to refuse typical, well-known reasons, she can do nothing but guess what reasons might persuade him. The burden of explanation seeks to resolve the latter, transparency issue. Steve should "elucidate [his] position, thereby helping the original speaker isolate the relevant mutually acceptable premises" (Rescorla 2009a, p. 100) ${ }^{27}$ or, in

\footnotetext{
${ }^{26}$ It is not correct to say that (cognitive) presumption $p$ exempts the proponent from any burden of arguing throughout the whole discussion. In my view, as far as the proponent is concerned, the presumption does two things. First, immediately after the opponent rejects $p$, it exempts the proponent from any burden of arguing. Second, in the discussion that follows, the presumption exempts the proponent from a burden of arguing in favor of $p$ (despite the fact that $p$ is the proponent's standpoint), but it does not exempt her from presenting arguments and objections against the opponent's views. In other words, presumptions could, perhaps, work in the proponent's favor by allowing her to win the mixed discussion by acting like a successful critic.

${ }^{27}$ Although Rescorla (2009a) seems to connect explanations to "rebuilding" the common ground (rapprochement), I believe that the purpose of explanation is more general. That is, even if explanations are legitimate primarily when (C) Petar Bodlović. Informal Logic, Vol. 40, No. 2 (2020), pp. 255-294
} 
van Laar and Krabbe's (2013) words, Steve should explain the "motivation for [his] position" (p. 213) in order to provide "a strategic advice" (p. 212) or "strategic guidance" (p. 213). This strategic advice should give Diane a chance to make a persuasive, dialectically adequate argument.

The considerations connected to the burden of explanation are different from ones related to the burden of arguing. Namely, providing an explanation "is not an attempt to convince the other and need not start from propositions conceded by the other" (van Laar and Krabbe 2013, p. 212). Thus, the burden of explanation does not require dialectically adequate, argumentative reasons, but merely explanatory reasons.

THE BURDEN OF EXPLANATION $(B o E)$ is the party's dialogical obligation to provide an explanatory reason for a position (view). ${ }^{28}$

common ground is at stake, the purpose of explaining might be to provide any premises that the proponent might use to make a persuasive argument. Sometimes, these premises can be acceptable only to the opponent and, thus, cannot represent new common ground. However, the proponent can still make use of them to make a persuasive case. Also, it must be noted that I deal with only one particular function of explanation, namely the function of improving "directiveness" (van Laar and Krabbe 2013) and thereby optimizing conditions for the constructive development of dialogue. However, one could use explanations for many different purposes. For instance, one could also offer inadequate, explanatory reasons to end any further discussion about the particular matter.

${ }^{28}$ As Godden notes, explanations are always permitted: "there is no prohibition, in standard 'symmetrical' dialectical games, against arguers motivating or explaining their doubts of other's standpoints" (2020, p. 4). But what makes explanations obligatory once presumptions are rejected? According to van Laar and Krabbe (2013), the opponent owes the proponent an explanation because, by rejecting initial presumption, she changes the original dialogical setting and makes it very difficult for the proponent to make a persuasive case. Similarly, Rescorla (2009a, pp. 97-98) argues that the opponent must try to achieve rapprochement (i.e., try to isolate mutually acceptable propositions) because this is a constitutive goal of reasoned discourse. Explanations are a means to achieve this goal, and they help the proponent to discharge her burden of proof successfully. In my opinion, the opponent must present the explanation only if the proponent requested the explanation in the previous turn. Otherwise, after rejecting a cognitive presumption, the opponent is obliged to give either argument or explanation.

(C) Petar Bodlović. Informal Logic, Vol. 40, No. 2 (2020), pp. 255-294 
For instance, after rejecting "Presumably, the Earth is globeshaped," Steve can offer the following explanation: "Our government fabricated the evidence that the Earth is globe-shaped." This explanatory reason is neither persuasive nor conceded by Diane, but it is helpful in resolving the aforementioned transparency issue: it will show Diane what to attack, as well as how to attack Steve's position adequately. ${ }^{29}$

( $\left.t_{1}\right) P$ : Presumably, $p$.

$\left(t_{2}\right) O$ : Reject: "Presumably, $p . "$

(t3) $O$ : Explanatory reason: $e$. [discharging the $B o E$ ]

Notice, for instance, that the previous explanation makes Steve committed to a more general claim, namely "Our government fabricates evidence about the shape of Earth." After realizing this, Diane might exploit Steve's commitment as a premise of her adequate counterargument. Imagine that she decides to construct an alternative conspiracy theory, and says: "But our government could have fabricated the Flat Earth theory just to keep the public away from the important stuff. The Flat Earth movement had the best media coverage on the day when our government passed the controversial law on public health. Don't you find this suspicious?" To be sure, Diane's counterargument does not show that the Earth is globe-shaped, but it might show that "The Earth is globe-shaped" and "The Earth is disc-shaped" must be equally acceptable to Steve given his commitment set or, in particular, his commitment that governments fabricate evidence. Since Diane has a presumption in her favour, this is all she needs to do to (successfully) discharge her burden of arguing and to prevent Steve from winning a discussion.

In the Flat Earth example, Steve's explanation, however bizarre, plays a constructive dialectical role because it helps Diane to participate in a discussion fruitfully. Also, it nicely coheres with the widely-accepted, Gricean view that argumentative discussion

\footnotetext{
${ }^{29}$ After Steve's explanation, Diane knows that to cast doubt on "The Earth is disc-shaped" she must, at some point, make a persuasive refutation of "Our government fabricated the evidence that the Earth is globe-shaped." More importantly, she can use Steve's explanation to derive adequate reasons for her arguments.
}

(C) Petar Bodlović. Informal Logic, Vol. 40, No. 2 (2020), pp. 255-294 
is a cooperative enterprise. For these two reasons, explaining seems like a reasonable dialectical choice in $t 3$. But if explaining is dialectically reasonable, then how can Steve be obliged to give an argument, as standard accounts of deontic function seem to suggest? If he is allowed to discharge the burden of explanation, how can he carry the burden of arguing (proof)? Do cognitive presumptions, ultimately, asymmetrically allocate the burden of arguing $(B o A)$ or the burden of explanation $(B o E)$ in $t_{3}$ ?

I believe that cognitive presumptions allocate neither of these burdens. Technically, once the opponent rejects a cognitive presumption, she is not immediately obliged to give an argument (in order to defend her position), and she is not immediately obliged to give an explanation (in order to provide strategic guidance). Since giving an argument and giving an explanation are both reasonable moves, I believe that the opponent's obligation is rather a disjunction: once she rejects a cognitive presumption in $t_{2}$, she is obliged either to give an argument or to explain the rejection in $t_{3}$. Put differently, the opponent incurs the burden of reasoning $(B o R)$, and she can discharge this burden in a more competitive (by discharging the $B O A$ ) or a more cooperative fashion (by discharging the $B o E$ ).

(t1)

$P$ : Presumably, $p$.

(t2)

$O$ : Reject: "Presumably, $p . "$

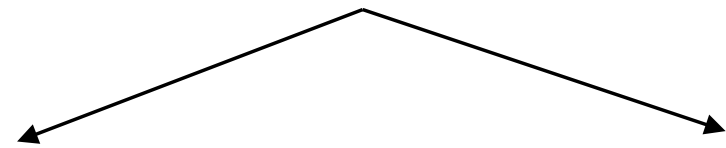

(t3) O: Argumentative reason: $a$. [=discharging the $B o A$.]

O: Explanatory reason: $e$. [= discharging the $B o E]$

Figure 1: A profile of dialogue: cognitive presumption

To be sure, the opponent might become obliged to argue in $t_{4}$ if the proponent requests an argument in $t_{3}$, but this would mean that the opponent's burden is conditional on the proponent's speech 
act. ${ }^{30}$ As long as the $B o A$ is supposed to be unconditionally allocated in $t_{3}$, I believe that the standard accounts are incorrect: in $t_{3}$, the opponent does not carry the $B o A$, but the more general $B o R$. This does not mean, however, that the opponent is exempted from the global burden of proof: if her final aim is to persuade the interlocutor and win the discussion, ultimately, she will be obliged to defend her standpoint with (sufficient) argument. But at the local level, in $t_{3}$, immediately after rejecting presumption, the opponent is permitted to present an explanation, as well as argument (and obliged to present either explanation or argument).

In conclusion, cognitive presumptions asymmetrically allocate the burden of proof in $t_{3}$ only if the burden of proof is interpreted in terms of BoR. As soon as we accept the usual, natural, more specific interpretation of the burden of proof in terms of $B o A$, standard accounts of the deontic function require revisions: cognitive presumptions do not asymmetrically allocate the burden of proof (in $t 3$ ). But what does this mean for the relationship between cognitive and practical presumptions? Are the opponents obliged to offer either explanations or arguments after rejecting practical presumptions, or do practical presumptions, unlike cognitive ones, asymmetrically allocate the burden of proof in the strict sense of the $B o A$ ?

\subsection{Practical presumptions, and the burden of explanation}

I argue that practical and cognitive presumptions have distinct deontic functions. The differences, however, are subtle. To make that clear, I need to distinguish between two views about when one could impose the burden of explanation on the challenger of a practical presumption. I call them a stricter view and a looser view.

According to a stricter view, a burden of explanation should only suffice when someone challenges a common ground proposition. Since the rejection of a widely-accepted (or mutuallyaccepted) proposition "counts as a substantial change of the nature of the dialogue" (van Laar and Krabbe 2013, p. 210), the opponent

\footnotetext{
${ }^{30}$ As briefly mentioned at the beginning of Sect. 4, it is unclear whether standard accounts of deontic function accept this idea.
}

(C) Petar Bodlović. Informal Logic, Vol. 40, No. 2 (2020), pp. 255-294 
must make sure that the new conditions of making a persuasive argument are transparent to the proponent. Nevertheless, none of these considerations directly applies to practical presumptions since, in the standard view, practical presumptions are not common ground propositions. Instead, they are "new intellectual resources" used at some later stage of deliberation to "proceed with our undertakings" (Godden 2017, p. 487). Accordingly, the opponent does not change the nature of the dialogue by rejecting a practical presumption, and the proponent's task of recognizing dialectically adequate reasons should not be especially demanding. Let us illustrate this on the Party example.

Alice: I would like to go to the party tonight.

Mark: I would like to go, too. But if it is uncertain whether John will be there, I would rather stay at home. His presence might entirely ruin our evening.

Alice: I agree. As long as there is a reasonable chance that John will come to the party, we should err on the side of safety and skip it. It is not worth the risk.

Mark: Can we somehow check whether he will attend the party?

Alice: I asked some colleagues, but they never texted me back. Anyway, we should decide quickly. The train is about to leave.

Mark: Isn't John out of town right now? He was bragging about his upcoming trip to Spain, remember?

Alice: Yes, but he must be at work day after tomorrow, so...

(tl) Mark: If he is back in town, he will probably be at that party.

Since we are uncertain about his whereabouts, let's just skip the party this time. [= "Presumably, John will be at the party."]

(t2) Alice: Well, I think we should go.

By rejecting "Presumably, John will be at the party" in turn $t_{2}$, Alice makes a surprising move. Although she, technically, does not challenge a common ground proposition, ${ }^{31}$ she rejects a posi-

\footnotetext{
${ }^{31}$ There are at least three reasons why "Presumably, John will be at the party" does not belong to the common ground. First, "John will be at the party" is certainly not a widely-accepted proposition supported by many epistemic (C) Petar Bodlović. Informal Logic, Vol. 40, No. 2 (2020), pp. 255-294
} 
tion that appears to follow from her commitments. ${ }^{32}$ So, Alice should provide a reason for her rejection, but is she allowed to offer (only) an explanatory reason? Does it suffice to discharge the burden of explanation?

If only attacks of common ground propositions might incur a burden of explanation, then it does not suffice to impose on the opponent the mere burden to explain her position. Namely, the purpose of explaining is to offer strategic guidance, but, when a practical presumption gets challenged, the proponent does not seem to need any strategic advice. Even before Alice gives any reason in $t_{3}$, Mark, in principle, has a pretty clear idea of what might persuade her to skip the party. Starting from the belief that Alice still wants to avoid John, Mark can use any reason which proves that John will definitely (or most probably) come to the party. He can, perhaps, call John and tell Alice the bad news, or provide evidence that John is already in town. Of course, Mark might be unable to give an adequate, persuasive argument at some particular point, but this is an entirely different matter. What is crucial is that he has a good idea of what, in principle, might constitute an adequate, persuasive argument and that, consequently, he does not desperately need strategic advice to resolve the transparency issue. Since this need underlies the burden of expla-

sources (like "The Earth is globe-shaped"). Second, "John will be at the party" is not a shared concession, i.e., the proposition accepted by Alice and Mark at the beginning of the dialogue. Third, even when we interpret this proposition in the pragmatic, action-oriented sense of "We should act as if John will be at the party," Alice and Mark still do not accept it at the beginning of a dialogue. At best, they accept a (presumptive) rule "If it is uncertain whether John will be at the party, then we should act as if John will be at the party" and then, in turn $t_{l}$, Mark derives presumption based on this rule and its antecedent (basic fact) "It is uncertain whether John will be at the party." In summary, a practical presumption is not a common ground premise (that should be) accepted before the main discussion to enable a desirable start of the discussion. Rather, it is a tentative conclusion drawn at some later point of the discussion, to enable a desirable end of deliberation (i.e., avoiding greater harm in the context of evidential uncertainty and pressure to make a timely decision).

${ }^{32}$ That is, for all that Mark knows, Alice seems committed to both a presumptive rule and the basic fact in turn $t_{2}$. Consequently, one would expect that she will not reject a presumption in $t_{2}$.

(C) Petar Bodlović. Informal Logic, Vol. 40, No. 2 (2020), pp. 255-294 
nation, explaining becomes irrelevant and, therefore, does not suffice in the Party example.

So, on the stricter view, explanation represents a means without an end: it is designed to resolve a dialectical problem that, once a practical presumption gets rejected, does not arise. For this reason, the opponent should not be allowed only to explain her rejection, and she must be obliged to present also an argument.

(t1) $P$ : Presumably, $p$.

(t2) O: Reject: "Presumably, $p$. ."

(t3) $O$ : Argumentative reason: $a$. [discharging the $B o A$ ]

Figure 2: A profile of dialogue: practical presumption (stricter view)

According to a looser view, the burden of explanation also suffices when a challenged proposition is not part of the common ground. To be sure, the proponents will especially need guidance when the common ground propositions get rejected, but dialectical rules should also permit explanations when common ground is not at stake, and the discussion is already underway. In principle, offering strategic advice is a cooperative move under any circumstances, and the dialectical rules should not penalize the opponent for being too cooperative. They must allow explanations and strategic advice even when the opponent's explanations and guidance are, perhaps, unnecessary.

But are practical presumptions, then, different from cognitive ones? If both types of presumptions permit explanations, as well as arguments, then, immediately after they are rejected, all presumptions place the general burden of reasoning on their opponents. Do cognitive and practical presumptions, under the looser interpretation of the burden of explanation, have the same deontic function? I propose the following answer: In the framework of an abstract dialectical model that is insensitive to the unique circumstances where practical presumptions operate, they do. However, in the framework of a dialectical model that takes into account the special circumstances of uncertainty and deliberation pressure, the deontic functions should differ. In $t 3$, immediately after the opponent rejects the practical presumption, explanations are permissible, but not dialectically desirable. That is, although the oppo- 
nent's explanations do not seem to violate any ground rules of reasonable discussion, they hardly contribute to the optimal resolution of deliberation in the circumstances of uncertainty and pressure. Hence, the rules of dialogue should strongly encourage the opponent to provide an argument in t3. Since this does not apply to cognitive cases, we can do justice to the differences between cognitive and practical presumptions, even on the looser view. In the profile below, I illustrate the opponent's permitted, but suboptimal response with a curved line.

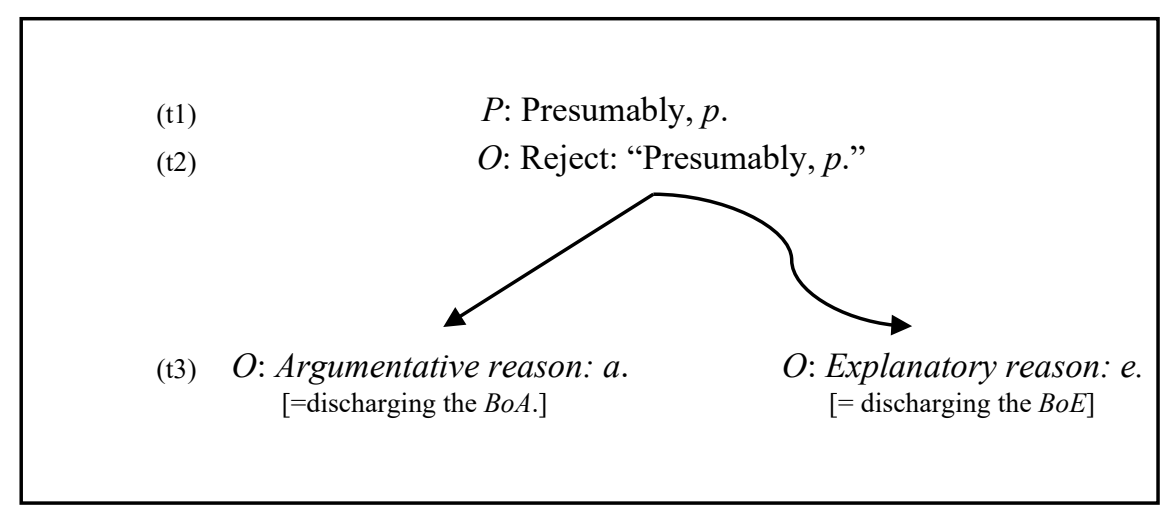

Figure 3: A profile of dialogue: practical presumption (looser view)

But what makes explanations suboptimal in practical cases, like the Party example? Why, exactly, should rules encourage Alice to support "We should go to the party" with argument rather than explanation? One reason was already mentioned: offering strategic guidance to Mark is simply not needed because Alice does not reject a common ground proposition. The more interesting reasons, however, are related to the lack of impact, or even a negative impact that the opponent's explanations could have on the resolution process. Usually, the opponent's explanations might be irrelevant or even detrimental for an optimal resolution of deliberation. How is this possible?

Let us remember that explanatory reasons are not aiming at persuasion and that, after rejecting a presumption in $t_{2}$, Alice might say the following: "The tea leaves tell me that John will not come to the party." Since Mark does not believe in reading tea 
leaves, her explanation is not persuasive, but it seems dialectically permissible. ${ }^{33}$ To see why her explanation is not dialectically desirable we must appreciate two unique deliberation limitations underlying the Party example: (1) uncertainty and (2) time pressure. Since Mark and Alice wish to avoid greater harm (seeing John), they will attend the party only if they are sufficiently certain that John will skip it, and, by turn $t_{2}$, they seem uncertain about John's whereabouts. Also, the time for gathering evidence about John's whereabouts is limited, and Mark and Alice must decide quickly (since the train is about to leave).

I believe that Alice's explanation is irrelevant because it cannot affect the uncertainty and, thereby, cannot change the default course of action. ${ }^{34}$ When the evidence is uncertain, practical presumptions produce a default course of action and, in the Party example, this action is skipping the party: if at the time when Mark and Alice must go to the train station, it remains (dialectically) uncertain whether John will come to the party, then Mark and Alice will skip the party. To take an alternative action, Mark and Alice must agree that it became sufficiently certain that John will not be at the party. But since reading tea leaves will not persuade Mark, the proposition "John will skip the party" will remain dialectically uncertain, and the original presumption will remain in place. As a result, the proposed explanation does not affect the outcome of deliberation: Mark and Alice will skip the party, i.e., they will do what they would have done even if the explanation was not offered. So, why offer explanations, even if they are al-

\footnotetext{
${ }^{33}$ From a dialectical viewpoint, Alice does not commit any argumentative fallacy and, more importantly, she is cooperative and transparent. She cooperates with Mark by presenting the evidence she considers relevant and, presumably, the only additional evidence she is capable of presenting at $t_{3}$ (offering, thereby, strategic advice).

${ }^{34}$ In the context of dialogue, certainty is understood in a dialectical sense: proposition $p$ is certain if, among other things, both parties agree that it is (likely) true. Otherwise, it is treated as uncertain. Notice that this does not exclude objective epistemic considerations. I do not claim that mutual agreement that $p$ is (likely) true is sufficient condition to render $p$ dialectically certain; instead, I claim that it is a necessary condition to render $p$ dialectically certain.
}

(C) Petar Bodlović. Informal Logic, Vol. 40, No. 2 (2020), pp. 255-294 
lowed? In the described circumstances, explaining seems pointless. $^{35}$

Not only is providing explanation irrelevant, but it is also detrimental. Practical presumptions arise when time is limited and, thereby, represents an especially valuable resource. In these special circumstances, it is usually not reasonable to spend time on giving (only) explanations since they, as we have seen, can hardly change the default outcome of deliberation. Given that parties want to improve their chances of arriving at the best decision, which might be different from a default decision, they should probably spend the time in a more constructive way. The first, obvious choice is to present and discuss arguments that are already at hand. If, in the turn $t_{3}$, Alice has both an explanation and an adequate argument up her sleeve, then she should present an argument. By doing so, Alice will have a better chance to persuade Mark, affect dialectical uncertainty, and move deliberation towards optimal resolution. The second, less obvious choice might be to spend time on finding arguments that are not already at hand. Suppose that in the turn $t_{3}$, Alice has a choice: to provide an explanation, or to search for reasons that might be relevant for making the best decision. For instance, instead of spending time discussing tea leaves, Alice might simply call John and ask him about his whereabouts. If Mark and Alice consider John reliable, acquiring this information will have a direct impact on making an optimal decision in the Party example.

Does this render a looser view implausible? If (only) explaining is typically irrelevant in the circumstances of uncertainty and detrimental in the circumstances of pressure, then perhaps (only) explaining should not be allowed? In my opinion, this conclusion is too extreme. Explanations should not be banned by dialectical rules because, at least sometimes, they can be persuasive (ade-

\footnotetext{
${ }^{35}$ What happens if Mark uses the information about tea leaves to persuade Alice that John's whereabouts are still uncertain? Does explanation, perhaps, affect the outcome of deliberation by giving strategic guidance to Mark? I believe that it does not. The presumption stays in place as long as Mark remains skeptical about the reliability of tea leaves and John's whereabouts, and this does not seem to depend on whether his future attempt to persuade Alice, by exploiting her explanation concerning tea leaves, is successful or not.
} 
quate) to a limited degree and represent weak arguments. That the proponent does not concede the opponent's explanatory reason could simply mean that she finds this reason adequate to a minimal degree. But in situations of evidential uncertainty, where any piece of evidence (however weak or inadequate) might make a difference and be significant to arrive at the best decision, explanations with limited persuasive force might be both relevant and constructive. So, as far as rejections of practical presumptions are concerned, explanations should be permitted but not recommended (in comparison to adequate arguments) since, at least sometimes, they might contribute to something more than providing strategic guidance.

To sum up, explaining can come with the high opportunity cost and be harmful for arriving at the best decision. When the opponent rejects a practical presumption, explaining is usually a waste of time, both figuratively and literally speaking. It is crucial to notice that similar concerns do not easily apply to cognitive presumptions. However bizarre, Steve's explanation "Our government fabricated the evidence that the Earth is globe-shaped" affects the further development of the dialogue in the Flat Earth example and since it provides much-needed guidance to Diane, its influence is quite positive. Also, it seems that Diane and Steve do not need to worry about approaching deadlines. Technically, their debate about the shape of Earth can last for years, and Steve is not irresponsibly wasting time by offering a single explanation (at least not in a sense distinctive to The Party example). In effect, two types of presumptions have different deontic functions.

THE DEONTIC FUNCTION OF COGNITIVE PRESUMPTION: After they are rejected in $t_{2}$, cognitive presumptions allocate the burden of reasoning $(B o R)$ on the opponent's side in $t_{3}$. This means that the opponent is obliged to discharge either the burden of arguing $(B o A)$ or the burden of explanation $(B o E)$.

THE DEONTIC FUNCTION OF PRACTICAL PRESUMPTION: After they are rejected in $t_{2}$, practical presumptions, in principle, allocate the burden of reasoning $(B o R)$ on the opponent's side in $t 3$. However, typically, given the particular circum- 


\section{Bodlović}

stances of uncertainty and deliberation pressure, the opponent should discharge the $B o A$ : dialectical rules should permit explanations and arguments in $t 3$, but strongly recommend arguments over explanations.

These characterizations of deontic functions are not complete. First of all, they deal only with the opponent's rights and obligations. But what about the proponent? Is the proponent of presumption indeed exempted from the burden of proof? In which sense of the term, and under which conditions? Can the opponent's explanation place the burden of proof on the proponent, or only an argument will suffice? Does the argument need to be sufficiently strong, or it only needs to be adequate? Moreover, the present characterizations do not explore the conditionality of the opponent's obligation. Is the opponent immediately obliged to give reasons in $t_{3}$, or does her obligation in $t_{4}$ depend on the proponent's request for reasons in $t_{3}$ ? And who gets to choose whether argumentative or explanatory reasons must be presented: the proponent or the opponent? The present paper starts from the assumption that standard accounts propose an unconditional allocation of the burden of proof, but this must be explored in more detail. Finally, the crucial concept of probative asymmetry, or "asymmetrical allocation" has not been explored at all.

However, even at this preliminary stage, our results show that standard accounts of presumption require qualifications. On the one hand, if standard accounts insist that presumptions allocate the burden of proof asymmetrically, then they seem committed to a rather loose and ambiguous notion of the burden of proof: whereas cognitive presumptions reverse the burden of proof in the sense of the burden of reasoning, practical presumptions reverse the burden of proof in the sense of the burden of arguing (at least in optimal scenarios). On the other hand, if standard accounts accept the natural conception of the burden of proof, as I believe they do, then their standard characterization of deontic function is inaccurate: immediately after they are rejected, only practical presumptions (should) asymmetrically allocate the burden of proof. This reveals that cognitive and practical presumptions potentially create different patterns of dialectical interaction. 


\section{Conclusion}

According to standard accounts, presumptions are dialectically privileged, yet defeasible, propositions: if the opponent rejects a presumption, she is supposed to carry the burden of proof, and the presumption is acceptable until the burden of proof is (successfully) discharged. Standard accounts acknowledge that there are various types of presumptions, but they treat the deontic function as a shared dialectical feature or some sort of common denominator. Put simply, once rejected, all presumptions are supposed to place the burden of proof on the opponents.

In this paper, I analysed the deontic function by taking into account (1) different types of presumption, and (2) distinct conceptions of the burden of proof. First, I argued that presumption, taken in the abstract sense, does not place the burden of proof on the opponent immediately after it is rejected. Rather, the opponent incurs the general burden of reasoning. Since the burden of proof is, typically, a narrower conception than the burden of reasoning, this conclusion is not entirely in line with the standard accounts. Second, I argued that cognitive and practical presumptions distribute different dialectical obligations. To be sure, they both place some sort of the burden of reasoning on the opponent, but whereas cognitive presumptions require either arguments or explanations, practical presumptions seem to require (or at least strongly recommend) arguments. Thus, at the level of a concrete dialogical implementation, the deontic uniqueness, proposed by standard accounts, does not hold. Different presumptions have distinct deontic functions.

The results of this paper are relevant for the argumentation theory, in particular, and philosophy, in general. In argumentation theory, for instance, they contribute to the normative study of the opponent's critical reactions, i.e. the "burden of criticism" (see Krabbe and van Laar 2011; van Laar and Krabbe 2013). In philosophy, they add to the ongoing discussion between dialectical foundationalists and dialectical egalitarianists. For obvious reasons, they contribute to dialectical study of presumptions. Nevertheless, the present results are provisional, and much additional work is needed to test their tenability. 


\section{Acknowledgments}

The earlier versions of this paper were presented at the Annual $\mathrm{PhD}$ Conference Groningen (Groningen, September 25 2019), as well as at the 12th OSSA conference Evidence, Persuasion \& Diversity (Windsor, June 3-6 2020). I thank the organizers of these conferences, as well as the participants for their constructive criticisms and recommendations. I am especially indebted to my supervisors dr. Jan Albert van Laar and dr. Barteld Kooi, my OSSA commentator dr. David Godden, the reviewers and editors of Informal logic (especially dr. J. Anthony Blair), and Karolina Kudlek. Finally, I thank the chair of the committee, dr. Sally Jackson, and the members of the committee for awarding the earlier version of this paper with the "J. Anthony Blair Prize" for an outstanding student paper.

\section{References}

Aijaz, I., J. McKeown-Green and A. Webster. 2013. Burdens of proof and the case for unevenness. Argumentation 27(3): 259282.

Bodlović, P. 2020a. Presumptions, burdens of proof, and explanations. OSSA Conference Archive 17: 1-22.

Bodlović, P. 2020b. On the differences between practical and cognitive presumptions. Argumentation. [Forthcoming].

Bermejo-Luque, L. 2019. On the Relationship between Presumptions and Burdens of Proof. In Presumptions and burdens of proof. An anthology of argumentation and the law, eds. H.V. Hansen, F.J. Kauffeld, J.B. Freeman, and L. Bermejo-Luque, 244-257. Tuscaloosa: The University of Alabama Press.

Blair, J.A. 2012. Argumentation as Rational Persuasion. Argumentation 26: 71-81.

Brown, R. 1970. The Burden of Proof. American Philosophical Quarterly 7(1): 74-82.

Cargile, J. 1997. On the Burden of Proof. Philosophy 72(279): 5983.

CNBC.com staff. 2016. Trump tweets new voter fraud claims, blasts CNN, but offers no evidence. URL accessed 9 November 
201: $\quad$ https://www.cnbc.com/2016/11/28/trump-tweets-newvoter-fraud-claims-blasts-cnn-but-offers-no-evidence.html.

Dare, T. and J. Kingsbury. 2008. Putting the Burden of Proof in Its Place: When Are Differential Allocations Legitimate? The Southern Journal of Philosophy XVI: 503-519.

Eemeren, F.H. van, R. Grootendorst and A. Francisca Snoeck Henkemans. 2002. Argumentation: Analysis, Evaluation, Presentation. Mahwah, New Jersey/London: Lawrence Erlbaum Associates.

Eemeren, F.H. van, and P. Houtlosser. 2002. Strategic Maneuvering with the burden of proof. In Advances in PragmaDialectics, ed. F. H. van Eemeren, 13-29. Sic Sat/Amsterdam.

Eemeren, F.H. van and R. Grootendorst. 2004. A Systematic Theory of Argumentation. The Pragma-Dialectical Approach. Cambridge: Cambridge UP.

Flew, A. 1972. The Presumption of Atheism. Canadian Journal of Philosophy 2(1): 29-46.

Freeman, J.B. 2005. Acceptable premises. Cambridge: Cambridge UP.

Godden, D. 2017. Presumption as a Modal Qualifier: Presumption, Inference, and Managing Epistemic Risk. Argumentation 31(3): 485-511.

Godden, D. 2019. Analyzing Presumption as a Modal Qualifier. In Presumptions and burdens of proof. An anthology of argumentation and the law, eds. H.V. Hansen, F.J. Kauffeld, J.B. Freeman, and L. Bermejo-Luque, 206-220. Tuscaloosa: The University of Alabama Press.

Godden, D. 2020. Commentary on Petar Bodlović: Presumptions, burdens of proof, and explanations. OSSA Conference Archive 18: 1-7.

Godden, D., and D. Walton. 2007. A theory of presumption for everyday argumentation. Pragmatics \& Cognition 15(2): 313346.

Goodwin, J. 2001. One Question, Two Answers. OSSA Conference Archive: 1-16.

Govier, T. 2010. A Practical Study of Argument ( $7^{\text {th }}$ edition). Wadsworth, Cengage Learning. 
Hahn, U. and M. Oaksford. 2007. The burden of proof and its role in argumentation. Argumentation 21(1): 39-61.

Hansen, H.V. 2019. Historical selections. In Presumptions and burdens of proof. An anthology of argumentation and the law, eds. H.V. Hansen, F.J. Kauffeld, J.B. Freeman, and L. Bermejo-Luque, 5-19. Tuscaloosa: The University of Alabama Press.

Johnson, R.H. 2000. Manifest rationality: a pragmatic theory of argument. Mahwah, New Jersey: Lawrence Erlbaum Associates, Inc.

Kauffeld, F.J. 1998. Presumptions and the Distribution of Argumentative Burdens in Acts of Proposing and Accusing. Argumentation 12(2): 245-266.

Kauffeld, F.J. 2003. The ordinary practice of presuming and presumption with special attention to veracity and the burden of proof. In Anyone who has a view: Theoretical contributions to the study of argumentation, eds. F. H. van Eemeren, et al, 133146. Dordrecht: Springer Science+Business Media.

Kauffeld, F.J. 2005. Presumptions and Shifting the Burden of Proof. Paper Presented at the IPrA Conference. URL accessed 10 October, 2019:

http://www2.arnes.si/ ffljzagar/Kauffeld_paper.pdf.

Kelly, T. 2005. Moorean facts and belief revision, or can the skeptic win? Philosophical Perspectives 19: 179-209.

Koplin, J. and M. Selgelid. 2015. Burden of proof in bioethics. Bioethics 29(9): 597-603.

Krabbe, E.C.W. and J.A. van Laar. 2011. The Ways of Criticism. Argumentation 25: 199-227.

Laar, J.A. van and E.C.W. Krabbe. 2013. The Burden of Criticism: Consequences of Taking a Critical Stance. Argumentation 27(2): 201-224.

Leite, A. 2005. A localist solution to the regress of epistemic justification. Australasian Journal of Philosophy 83(3): 395421.

Lewiński, M. 2017. Argumentation Theory Without Presumptions. Argumentation 31(3): 591-613.

Lycan, W.G. 2003. Free will and the burden of proof. Royal Institute of Philosophy Supplement 53: 107-122. 
Macagno, F. and D. Walton. 2011. Reasoning from paradigms and negative evidence. Pragmatics \& Cognition 19(1): 92-116.

Pascal, B. 2004. Pensées (edited and translated by Roger Ariew). Indianapolis/Cambridge: Hackett Publishing Company.

Pigliucci, M. and M. Boudry. 2014. Prove it! The Burden of Proof Game in Science vs. Pseudoscience Disputes. Philosophia 42(2): 487-502.

Pinto, R.C. 2001. Argument, inference and dialectic: collected papers on informal logic (with an introduction by Hans V. Hansen). Dordrecht: Kluwer.

Prakken, H. and G. Sartor. 2006. Presumptions and Burdens of Proof. In Legal Knowledge and Information Systems: JURIX 2006: The Nineteenth Annual Conference, ed. T. M. van Engers, 21-30. Amsterdam: IOS Press.

Räikkä, J. 1997. Burden of Proof Rules in Social Criticism. Argumentation 11: 463-477.

Räikkä, J. 2005. Global Justice and the Logic of the Burden of Proof. Metaphilosophy 36(1/2): 228-239.

Rescher, N. 1977. Dialectics: A controversy-oriented approach to the theory of knowledge. Albany, NY: SUNY Press.

Rescher, N. 2006. Presumption and the practices of tentative cognition. Cambridge: Cambridge UP.

Rescorla, M. 2009a. Shifting the burden of proof? Philosophical Quarterly 59(234): 86-109.

Rescorla, M. 2009b. Epistemic and dialectical regress. Australasian Journal of Philosophy 87(1): 43-60.

Scriven, M. 1966. Primary philosophy. New York: McGraw-Hill.

Strong, J.W. 1992. McCormick on Evidence (4 ${ }^{\text {th }}$ edition). St Paul, Minnesota: West Publishing Co.

Thayer, J.B. 2019. The Burden of Proof. In Presumptions and burdens of proof. An anthology of argumentation and the law, eds. H.V. Hansen, F.J. Kauffeld, J.B. Freeman, and L. Bermejo-Luque, 74-83. Tuscaloosa: The University of Alabama Press.

Tseronis, A. 2009. Qualifying Standpoints. Stance adverbs as a presentational device for managing the burden of proof (doctoral thesis). Utrecht: LOT.

Ullmann-Margalit, E. 1983. On presumption. Journal of Philosophy 80(3): 143-163. 
Walton, D. 1988. Burden of Proof. Argumentation 2(2): 233-254.

Walton, D. 1990. What is reasoning? What is an argument? The Journal of Philosophy 87(8): 399-419.

Walton, D. 2014. Burden of proof, presumption and argumentation. New York: Cambridge UP.

Whatley, R. 1963. Elements of Rhetoric ( $7^{\text {th }}$ ed.). Carbondale IL: Southern Illinois University Press.

Williamson T. 2011. Philosophical expertise and the burden of proof. Metaphilosophy 42(3): 215-229. 